\title{
Educação em Ciência, Tecnologia e Sociedade (CTS) na América Latina: Uma perspectiva humanística e emancipadora ${ }^{1}$
}

\author{
In memoriam Wildson Luiz Pereira dos Santos \\ Leonardo Fabio Martínez Pérez²
}

Escrever umas palavras com viés acadêmico para um colega e amigo que tem nos deixado um legado significativo, resulta difícil e traz, à nossa memória, lembranças compartilhadas sobre a necessária humanização e transformação da Educação em Ciências. Como todos os intelectuais comprometidos no movimento Ciência-Tecnologia-Sociedade (СTS), conheci Wildson por meio do seu texto legendário intitulado: Educação em Química: compromisso com a cidadania, obra publicada em 1997 e cujas linhas nos convidam a discutir sobre a educação CTS no âmbito internacional e latino-americano. Em seguida, tive a oportunidade de participar com Wildson do Encontro Nacional de Educação em Química, realizado no ano de 2008, em Curitiba/Brasil e, felizmente, contei com a sua presença como membro titular da banca em minha tese de doutorado, apresentada em agosto de 2010. Dessa forma começou meu contato com a vasta e representativa obra de um grande pensador freireano e, consequentemente, aproximei-me de um ser humano simples, fraterno, mas, sobretudo, muito comprometido com um projeto educativo crítico e emancipador.

Junto com outros colegas brasileiros, acompanhamos Wildson na importantíssima ação de concretar um posicionamento latino-americano nos Seminários Ibero-americanos da Ciência, Tecnologia e Sociedade. O grande esforço do nosso colega foi bastante evidente no bem-sucedido seminário realizado em Brasília, em julho do ano 2010; desde aquele momento converteu-se em um defensor incansável da educação CTS, mantendo coerentemente seus ideais na Associação lbero-americana CTS, na qual participou como membro do conselho diretivo até os seus últimos dias.

A obra de Wildson é difícil de descrever, mas ao correr o risco de fazê-lo, podemos identificar cinco temáticas fundamentais: a caracterização do desenvolvimento do movimento CTS no contexto latino-americano; a educação em ciências para a formação cidadã; a construção coletiva dos livros didáticos de Química

\footnotetext{
Agradecimento especial ao professor Marcos Fernandes Sobrinho, pela revisão e correção do texto.

2 Profesor del Departamento de Química y del DIE de la Universidad Pedagógica Nacional, Bogotá-Colombia. Doctor en Educación en Ciencias. lemartinez@pedagogica.edu.co
} 
com enfoque CTS; a abordagem dos assuntos sociocientificos; e, finalmente, as relações entre a educação CTS e a educação ambiental.

Em Santos e Schnetzler (2003) temos uma contextualização sobre a origem, desenvolvimento e consolidação histórica da educação CTS no contexto latino-americano. Ali existe uma ênfase na formação de sujeitos comprometidos com sua própria cidadania, a qual representa uma conquista do ser humano como sujeito de direitos. A contribuição principal desta obra está representada pela formulação de um novo paradigma à educação em química, orientada para a formação da cidadania, baseando-se em cinco princípios fundamentais: (1) a participação ativa dos estudantes como cidadãos responsáveis na tomada de decisões relacionadas com o desenvolvimento cientifico e tecnológico; (2) a Abordagem dos temas químicos em uma visão interdisciplinar; (3) A contextualização social dos conteúdos químicos; (4) $\bigcirc$ desenvolvimento de procedimentos baseados no construtivismo; e (5) $\bigcirc$ planejamento e progresso dos processos de ensino-aprendizagem como inerentes ao exercício do professor, como pesquisador da sua pratica.

Os princípios mencionados anteriormente foram cristalizados na construção coletiva de livros didáticos realizados com professores e pesquisadores que atualmente apoiam a Educação em Química, no Ensino Médio do Brasil (Santos e Mól, 2013a, 2013b, 2013c). Esses livros abordam os conceitos, teorias e modelos centrais da química de maneira articulada com os aspetos socioambientais, tais como: $\bigcirc$ consumo sustentável; a polvição atmosférica; as propriedades das sustâncias e a agricultura; os produtos químicos; os recursos energéticos e a energia nuclear; os alimentos e as funções orgânicas; a química na beleza e na saúde; a indústria química, baterias e contaminação; a nanotecnologia. $\bigcirc$ ensino destas temáticas interessantes para os estudantes implicam, necessariamente, uma formação do professor, fundamentada na construção da autonomia docente; o desenvolvimento do ensino desde a pesquisa temática proposta por Paulo Freire; a interdisciplinaridade; e o conhecimento sobre as interações ciência, tecnologia, sociedade e ambiente.

Enquanto à aproximação dos assuntos sociocientíficos, Santos e Mortimer (2002) destacam a importância de trabalhar na aula, temas problemáticos científicos e(ou) tecnológicos, de tal maneira que permitam questionar a supervalorização da ciência moderna como o mito da neutralidade do progresso tecnocientífico. Nessa orientação, Santos (2008) propõe trabalhar esses assuntos de acordo com as suas dimensões políticas dirigidas à construção de uma sociedade com justiça e igualdade social. Além disso, essa abordagem apresenta uma ressignificação da educação em ciências conforme uma perspectiva libertadora, posto que o seu caráter político favorece o questionamento da ideologia imposta pela racionalidade tecnocrática.

As contribuições de Santos e Mortimer (2009) consideram a abordagem de 
à construção de conhecimentos e capacidades aos cidadãos, de tal forma que Ihes permitam participar responsavelmente nas controvérsias cientificas e tecnológicas do mundo contemporâneo.

Por outra parte, os aportes de Santos (2012) sobre as relações entre a educação CTS e a educação ambiental, podemos destacar que as duas perspectivas se aproximam desde uma visão crítica da educação porque têm objetivos semeIhantes orientados à construção de uma sociedade mais justa e fundamentada em princípios da sustentabilidade, implicando a superação do modelo de desenvolvimento atual, que tem usado a ciência e a tecnologia como instrumentos de progresso econômico e que favorecem a produção de quaisquer tipos de elementos presentes nas práticas altamente consumistas dos cidadãos. Muito além das diferentes denominações que possam se atribuir à educação CTS, O mais importante é construir um significado que seja possível a formação cidadã dos estudantes nos diferentes níveis educativos, de maneira tal que os capacitem para a transformação das desigualdades das sociedades atuais, especialmente as latino-americanas.

pensamento aberto e dialógico do Professor Wildson possibilita uma apresentação dos artigos que compõem o seguinte número da TED, já que alguns deles estão relacionados diretamente com a sua obra. Começamos com o artigo sobre as concepções da natureza da ciência, assunto que tem sido estudado como uma preocupação da educação CTS. Nele é apreciada uma análise das concepções de cinco professores de química que trabalham na educação chilena; expõem-se tensões frente às dimensões de pesquisa e os postulados construtivistas - relativistas/empiristas - realistas. Outro artigo relacionado com a obra do professor Wildson é aquele sobre as salas verdes como estruturas democratizadas para o acesso à informação socioambiental; além de entender o mesmo como um artefato cognitivo na educação ambiental que permita conhecer a atividade da formação dos educadores ambientais no Brasil. Também se ressalta o artigo sobre as imagens da ciência nos textos universitários, que observou a necessidade de reconhecer o sentido histórico do conhecimento e a pertinência da atividade experimental.

Finalmente, convidam-se os leitores a estudarem criticamente o conteúdo dos artigos publicados na presente edição e, assim como fez o nosso colega Wildson que, além do seu importante legado acadêmico na educação CTS, contribuiu com a comunidade de pesquisadores e professores da educação em ciências e tecnologia, em suas diferentes palestras e participações nos coletivos das avaliações de publicações cientificas, tais como as representadas pela revista TED. 


\section{Referências}

Santos, W. (2008). Educação Científica Humanística em Uma Perspectiva Freireana: Resgatando a Função do Ensino de cts. Alexandria Revista de Educação em Ciência e Tecnologia, 1(1), 109-131.

Santos, W. (2012). Significados da educação científica com enfoque cts. En: Santos, W y Auler, D. CTS e Educação científica: desáfios, tendências e resultados de pesquisa. Brasilia: Editora UnB.

Santos, W. \& Mól, G. (Coord.). (2013a). Química Cidadã Ensino Médio (1 a série, 2 ed. v. I). São Paulo: AJS.

Santos, W. \& Mól, G. (Coord.). (2013b). Química Cidadã Ensino Médio (1 a série, 2 ed., v. II). São Paulo: AJS.

Santos, W. \& Mól, G. (Coord). (2013c). Química Cidadã Ensino médio (3ª série, 2 ed., v. III). São Paulo, Brasil: AJS.

Santos, W. \& Mortimer, E. (2002). Uma análise de pressupostos teóricos da abordagem C-T-S (Ciência - Tecnologia - Sociedade) no contexto da educação brasileira. Ensaio, 2(2), 1-23.

Santos, W. \& Mortimer, E. (2009). Abordagem de aspectos sociocientíficos em aulas de ciências: possibilidades e limitações. Investigações em Ensino de Ciências, 14(2), 191-218.

Santos, W. \& Schenetzler, R. (2003). Educação em química: compromisso com a cidadania (3. ${ }^{a}$ ed.). liuí. RS: Unijui. 